\title{
Monte Carlo Techniques in Computational Stochastic Mechanics
}

\author{
J.E. Hurtado \\ Facultad de Ingeniería y Arquitectura \\ Universidad Nacional de Colombia, Manizales, Colombia \\ A.H. Barbat \\ Departmento de Resistencia de Materiales y Estructuras en la Ingeniería \\ Universidad Politécnica de Cataluña, 08034 Barcelona, España
}

\section{Summary}

A state of the art on simulation methods in stochastic structural analysis is presented. The purpose of the paper is to review some of the different methods available for analysing the effects of randomness of models and data in structural analysis. While most of these techniques can be grouped under the general name of Monte Carlo methods, the several published algorithms are more suitable to some objectives of analysis than to others in each case. These objectives have been classified into the foolowing cathegories: (1), The Statistical Description of the structural scattering, a primary analysis in which the uncertain parameters are treated as random variables; (2) The consideration of the spatial variability of the random parameters, that must then be modelled as Random Fields (Stochastic Finite Elements); (3) The advanced Monte Carlo methods for calculating the usually very low failure probabilities (Reliability Analysis) and, (4), a deterministic technique that depart from the random nature of the above methods, but which can be linked with them in some cases, known as the Response Surface Method. All of these techniques are critically examined and discussed. The concluding remarks point out some research needs in the field from the authors' point of view.

\section{INTRODUCTION}

The purpose of the present paper is to expose succintly the state of the art of the application of simulation techniques in Stochastic Mechanics - a field of Mechanics related with methods for dealing with the inherent uncertainties of loads, material properties, geometry and human factors in the design of structures. The document has been divided into the following sections, according to the different objectives of analysis:

1. Statistical Description.

2. Stochastic Finite Elements.

3. Reliability Analysis.

4. Response Surface Method.

With the exception of the method to which the fourth section is devoted, which is a planned, deterministic simulation design, the techniques discussed in rest of the sections can be grouped under the name of Monte Carlo - a name taken after the famous casino. This method has for long been recognized as the most exact method for all the calculations that require the knowledge of the probability distribution of responses of uncertain systems to uncertain inputs. This is due to the fact that, according to a good definition, "the next best situation to having the probability distribution of a certain random quantity is to have a corresponding large population" (Ghanem and Spanos 1991).

While the conventional Probabilistic Structural Analysis (PSA) considers the uncertain quantitites (elastic moduli, loads, etc.) as random variables, in Stochastic Finite Element Analysis (SFEA) they are modelled as random fields, that is, as sequences of random 
variables spread over the surface or volume of the structural object, with a defined correlation structure. By this label it can be denoted also loads varying randomy with time, usually classified as random process. On the other hand, the Response Surface Method can serve to different purposes in the analysis and design of structural systems, such as those of Structural Optimization, Statistical Description, etc. In the present context it has been specially useful for Reliability Analysis in connection with Monte Carlo techniques as it will be described in the following sections.

For the sake of readability only the most contributing references according to the authors' judgement are quoted in the text. Many other references appear at the end of the document, which convey supplementary information that can be useful to the interested reader.

\section{STATISTICAL DESCRIPTION}

A primary analysis of the uncertainty of the response of a structure due to the randomness of the model parameters is that of its statistical description. This can give a complete and quite useful picture of the statistical relationships linking the input and output variables of the structural model, which provides in some cases surprising insights of the hidden and winding paths of randomness into the structure. As will be done in the rest of the sections of the present document, we will firstly comment the analytical techniques existing for coping with the problem at hand and then we will concentrate on the correspondent Monte Carlo methods.

It can be said without simplification that the most common analytical method for the assessment of statistical measures of response uncertainty of structures is the Perturbation Technique, which has relates the input and expansion provides a (Augusti et al.) 1984: the truncation of the ser
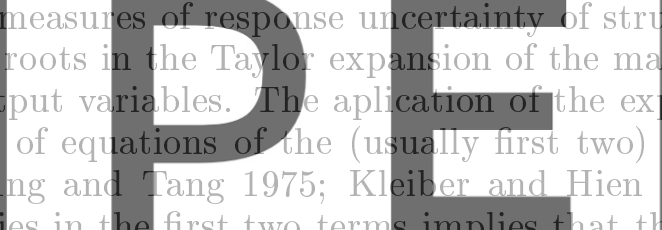

is limited to those cases in which the random input variables have very low coefficients of

is more restrictive in the case of nonlinear systems.

In order to have a statistical scenario of the response of any structural system the most accurate and general method is the Monte Carlo simulation. Since the joint probability distribution of the responses is not available in many cases, except in the most simple ones, and since the possibility of fast and parallel calculations of complex structures has fantastically increased in the last years, the rejection of Monte Carlo techniques that is commonly found in the technical literature of the past decades has become obsolete, and the method appears to be quite promising in the analysis of uncertain systems of any kind.

The general idea of the Monte Carlo method can be summarized as follows: Let the responses $\boldsymbol{y}$ of a system depend on a set of random variables $\boldsymbol{x}$, whose marginal probabilistic description is known. By means of well tested algorithms (Rubinstein 1981; Ripley 1987; Bratley et al. 1987) a large population of samples of each of these variables can be generated, in such a way that their histograms approach the marginal and joint distributions the closer, the larger the population. An equally large population of output responses can be obtained by making use of the deterministic code of analysis of the system each time with a different set of random deviates of the input variables.

There are two general methods for generating random variates corresponding to marginal distributions: the Inversion and the Rejection methods. In the Inversion Method (see Figure 1) uniform random numbers $u_{i}$ are generated in the range $(0,1)$ and the corresponding variates are calculated by inversion of the distribution function of the variable. The Rejection 


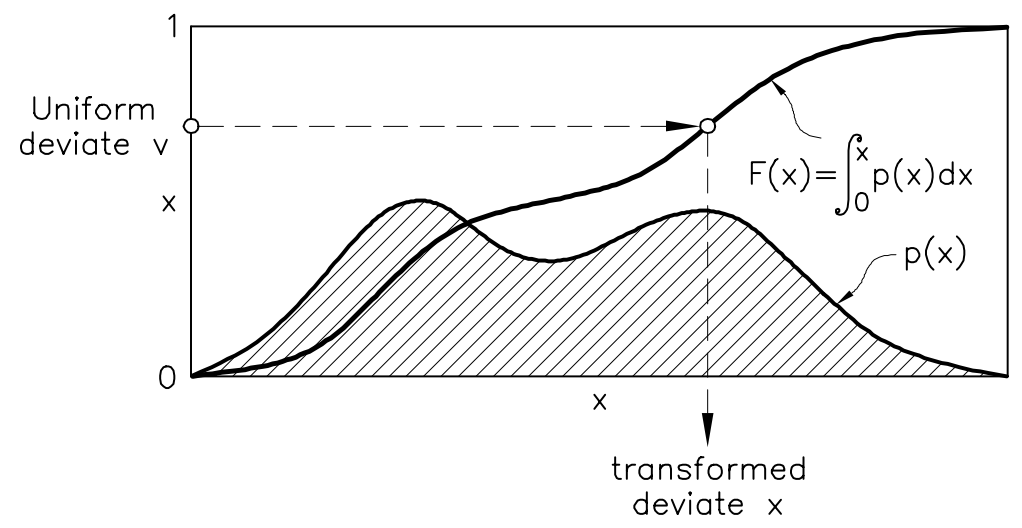

Figure 1. Inversion method for generating random variates

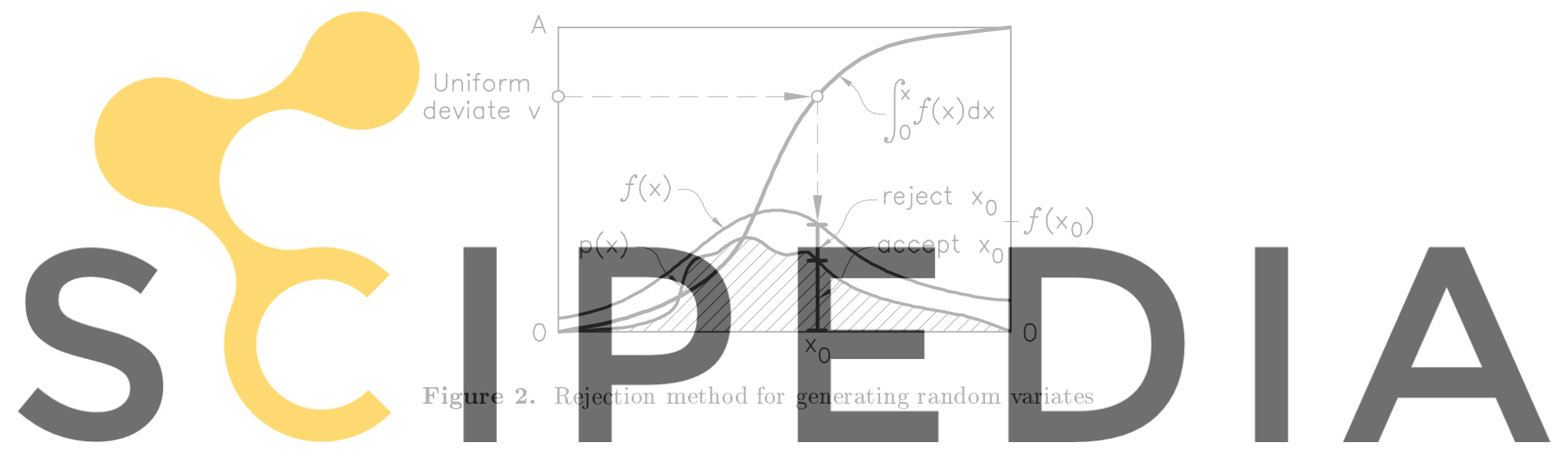

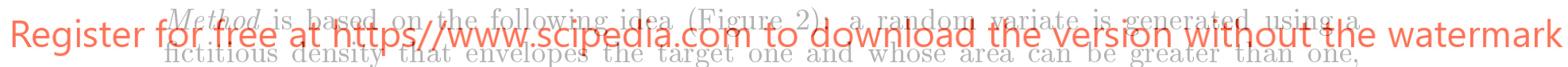
thus indicating that it is not a true density function but only a numerical device; the generated deviate is accepted with a specified probability that depends on the ratio of the true and fictitious densities. But in many instances methods for generating variates that are specific for each type of density are preferred (Ripley 1987).

One of the main handicaps encountered in the Stochastic Analysis of structures is the ignorance of the joint density function of all the random variables implied in a specific case, which are commonly described solely by their marginal distribution (Der Kiureghian and Liu 1986). The most frequently invoked technique to estimate the required joint density is by far the Nataf's model (Nataf 1962), in which use is made of the multidimensional Gaussian distribution with correlation coefficients modified according to the nonlinear transformation linking the given marginal and Gaussian densities. The corresponding samples of the correlated variables can then be generated by means of this approximate distribution.

Formulated as in the previous paragraphs the method is known as Simple Random Sampling because no optimization has been applied to the population with the aim of reducing its size without sacrifying the quality of the statistical description of the structural behavior in the whole input variable space. Figure 3 shows a typical "anthill" obtained by this technique. While this technique can be fast for reliability analysis of single components or even structures with a reduced number of degrees of freedom, as it is done in the software provided in the book of Marek et al. (1996), it is too costly for the case of large structures.

The following techniques have been proposed to reduce the population: 
1. Stratified Sampling (Rubinstein 1981). In this case the whole space of each variable is divided into subsets of equal probability. Then an outcome is generated from each subset and the analysis is performed with the corresponding sets of points.

2. Latin Hypercube Sampling (Iman and Canover 1980; Bazant and Liu 1985) This method represents an even more drastic reduction of the sampled population because each subset number (identified with a latin letter, whence the name of the algorithm) of each random variable is combined with other subset numbers of the rest of the variables only once in a randomized way. A variant of the method has been proposed (Florian 1992). In it a Cholesky factorization is applied to the correlation matrix of the permuted ranks of the input variables, in order to diminish the relatively high correlation resulting from the drastic reduction of the population with respect to the conventional method.

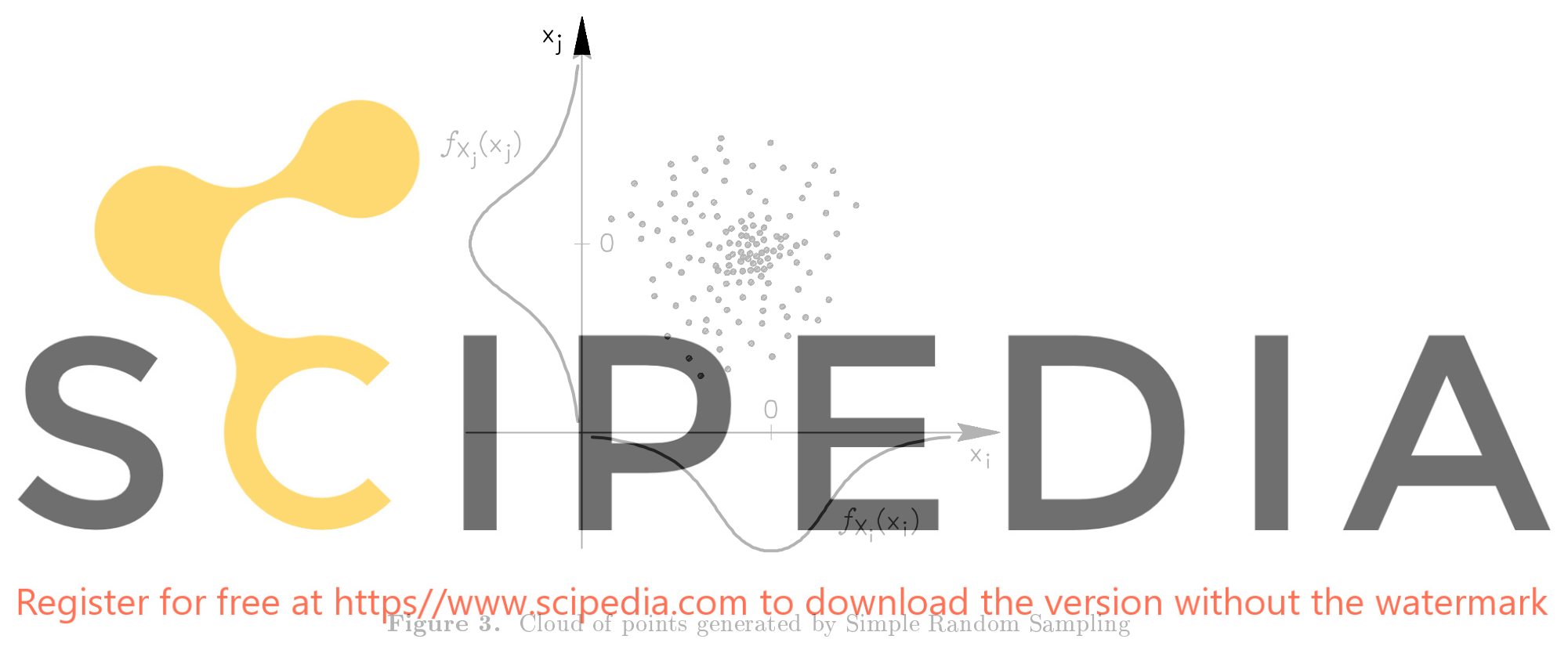

3. Descriptive Sampling (Zina 1995). This method is quite similar to the previous one, the difference between them lying in the way of generating the permutation matrix of the ranks. Figures 4 and 5 illustrate the way in which samples are generated by Stratified Sampling and the other two methods. It is important to say that in all of them the sample inside a rank is taken either from the its middle or randomly from it.

\section{STOCHASTIC FINITE ELEMENTS}

The Stochastic Finite Element (SFE) analysis has become a very active area of research in the general field of Computational Stochastic Mechanics in the last years. As explained in the Introduction, the consideration of randomness in this area is more elaborate than in the conventional Probabilistic Structural Analysis, since it is assumed that the parameters of the model (loads, material properties or geometry) have a random spatial variation. This means that the parameters are considered as random fields rather than random variables as they are in conventional PSA. In spite of the fact that the label SFE has been used in the sense of conventional PSA, it is employed today almost exclusively for denoting this kind of probabilistic description (Casciatti and Faravelli 1990; Ghanem and Spanos 1991; Kleiber and Hien 1992). 


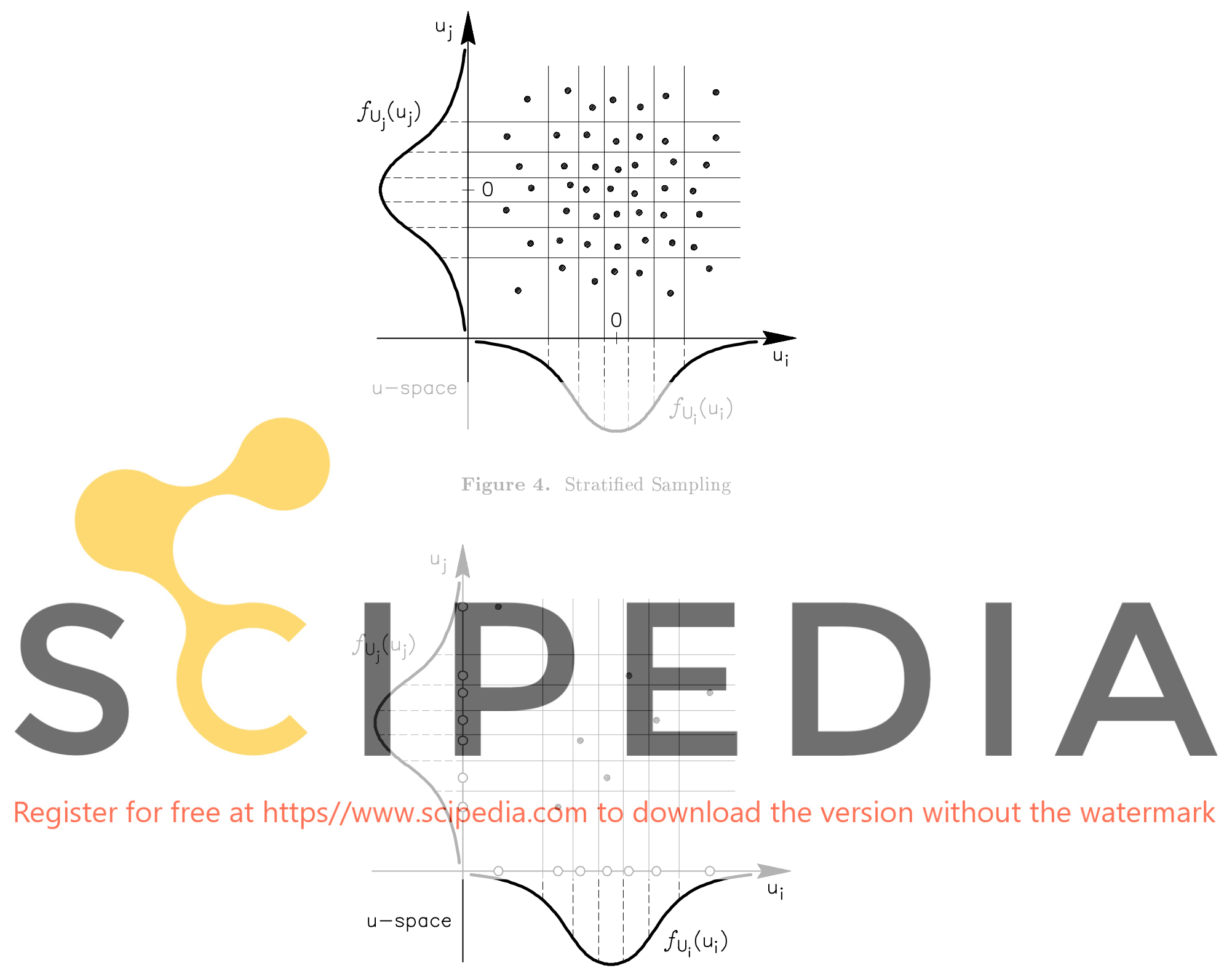

Figure 5. Latin Hypercube and Descriptive Sampling

Since either the analytical as well as the simulation methods for analysing the response of a system modelled by random fields use some stochastic notions that are not common in the engineering practice, a brief description of them is in order. The concept of Random Field stands for an indexed random variable or vector. The index can be that of time, space or both, and the dimension of the vector can be as large as the number of the correlated random indexed values. For example, the gust preassure on an aircraft wing is a random field whose only variable is the velocity, which is indexed on the space coordinates and, in the nonstationary case, on time. The thickness and the cross area of a shell constitute a twovariate random field indexed in two space coordinates, which can not be treated separately since they are mutually dependent. In the sequel we will restrict ourselves to uni-variate random fields. 
The value $x\left(\boldsymbol{s}_{i}\right)$ of the random field $x$ in the $m$-dimensional space position defined by $\boldsymbol{s}_{i}=\left[s_{1}, s_{2}, \cdots s_{m}\right]_{i}$ can be considered as a random variable. Then, the stochastic field will be defined by the probability distribution of $x\left(\boldsymbol{s}_{i}\right)$ as such, as well as that of the sets $\left[x\left(\boldsymbol{s}_{i}\right), x\left(\boldsymbol{s}_{j}\right)\right],\left[x\left(\boldsymbol{s}_{i}\right), x\left(\boldsymbol{s}_{j}\right), x\left(\boldsymbol{s}_{k}\right)\right]$, etc. This means that the complete description of the field requires the knowledge of the $n$-dimensional joint probability distributions of the values of the field at $n$ points of the indexing variable. Since in any real problem the value of $n$ tends to infinity, this is of course an exigency difficult to accomplish in practice.

A simplification of this high dimensional problem can be obtained when attention is given only to the two first joint moments of the variables $x\left(\boldsymbol{s}_{i}\right), x\left(\boldsymbol{s}_{j}\right)$. And an even more drastic simplification results from the assumption that these variables follow a Gaussian distribution, because any moment of order greater than two can be determined by the first two. It is for this reason that random fields are usually considered as Gaussian. The first central moment is then defined by

$$
\mathrm{E}\{x(s)\}
$$

and it corresponds to the mean value of the field, while the second is a measure of the degree of correlation of the variables $x\left(s_{i}\right)$ and $x\left(s_{j}\right)$

$$
R\left(s_{i}, s_{j}\right)=\mathrm{E}\left\{x\left(s_{i}\right) x\left(s_{j}\right)\right\}
$$

It is called the Autocorrelation Function of the field. When it can be expressed independently of the value of $s_{i}, s_{j}$ and only as a function of the differences $\xi=x_{1 j}-x_{1 i}, \eta=x_{2 j}-x_{2 i}$, etc., the field is called homogeneous, in the sense that the degree of correlation of two random variables depends only on the distance between them. That is the case when, for example, the randomness of a $\mathrm{p}$ boundaries, holes, etc The autocorrelation dimensions)
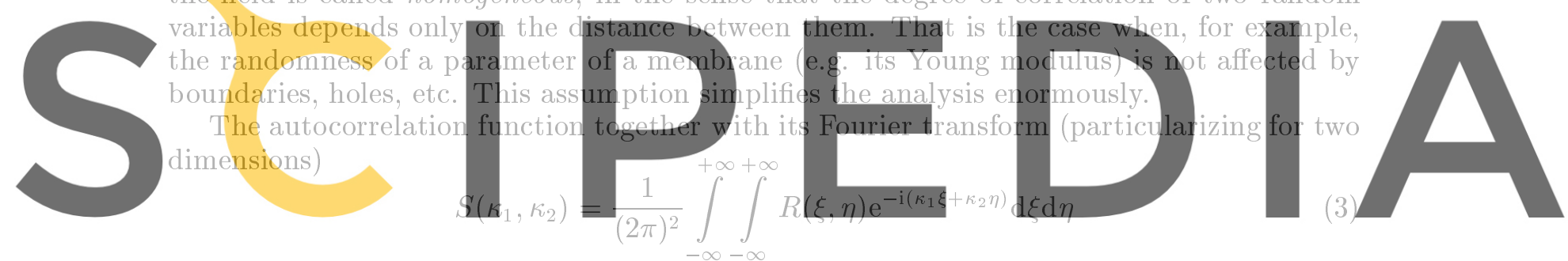

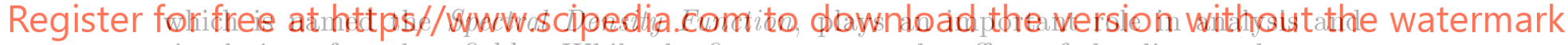
simulation of random fields. While the first measures the effect of the distance between points on their mutual interaction, the second translates this measure to the wave number $\kappa$ or the frequency $\omega$ spaces. In the analysis of random signals the spectral density is a measure of the energy associated to each frequency, in such a way that the total energy is proportional to the variance of the signal by virtue of the Parseval's theorem. Thus, the values of the spectral density in the present case correspond to the contribution of each wave number to the total variance of the field, which is a primary measure of its randomness. It is important to observe that the random fields so specified in SFEA are related to those employed in other areas of stochastic research, such a Signal Processing and Image Analysis, in which Markov, Poisson and Gibbs fields are commonly adopted (Winkler 1995) A monograph by Vanmarcke (1983) is usually quoted as the main reference text on random fields from an engineering point of view. The interested reader is referred to that work for an in-depth study of the subject. In particular the author treats in detail the role played by the local averages in the analysis of the random fields. Suppose a material property $X(s)$, such as porosity, has a random spatial variation along the line axis $s$. Some laboratory test performed on samples of the material will measure in fact an average of the field in the lenght $S$ of the tested piece

$$
X_{S}(s)=\frac{1}{S} \int_{s-\frac{S}{2}}^{s+\frac{S}{2}} X(u) \mathrm{d} u
$$


At this point it must be taken into account that the finite element size imposes also an average of the random field variation of the structural property or load in its dominion. As Figure 6 shows, the randomness of the moving average process $X_{S}(s)$ will be less than that of the process $X(s)$, implying that a way to reconstruct the real spatial random variation of the process from the test analysis must be found. The variance function is introduced as the ratio of the variances of the two processes

$$
\gamma(S)=\frac{\sigma_{S}^{2}}{\sigma^{2}}
$$

and the scale of fluctuation defined by

$$
\theta=\lim _{S \rightarrow \infty} S \gamma(S)
$$

will be an indirect measure of the correlation lenght of the original process. Important random field models of structural systems properties are specified in terms of this parameter.
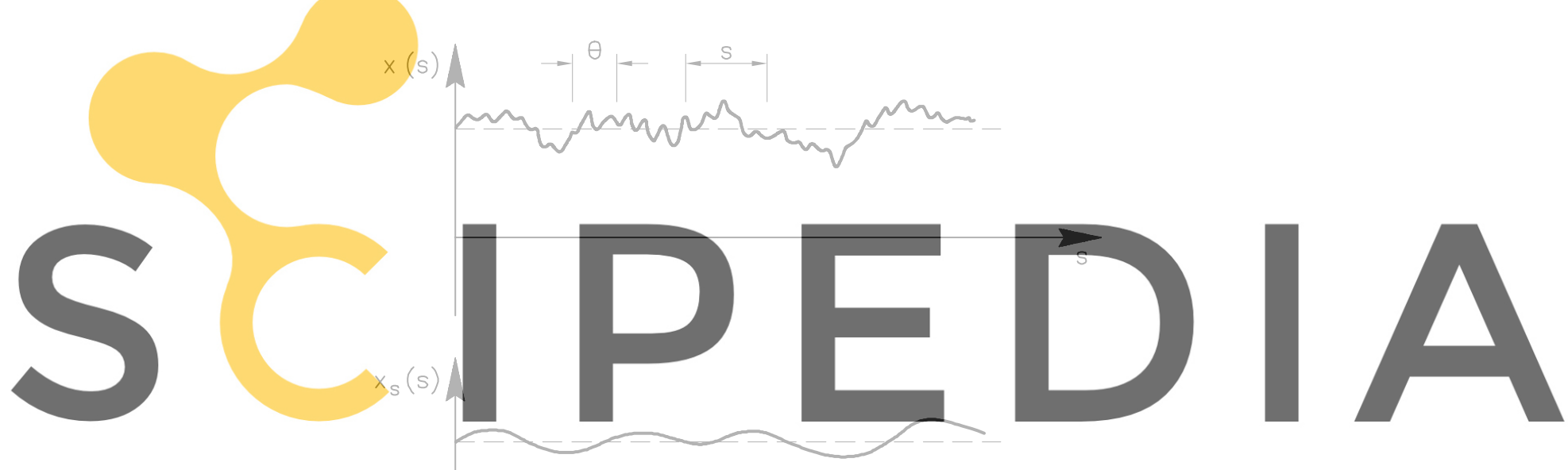

Register for free at https//www.scipedia.com to download the version without the watermark

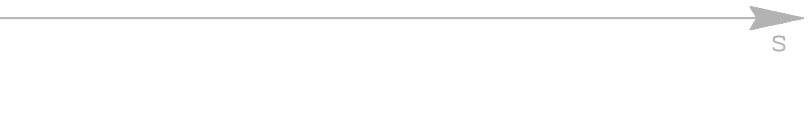

Figure 6. Random field and local averages

Once the random field nature of the spatial variability of the structural model parameters has been described, the problem that follows is to obtain a probability description of the response. As it was done in the previous section, a brief comment on the analytical methods developped for dealing with this problem will be first presented before treating the Monte Carlo techniques in more detail.

The majority of the procedures published up to date for analysing the influence of the spatial variability of the material properties and loads on the system response are also of the perturbation type (Hasselman and Hart 1970, Nakagiri and Hisada 1982, Liu et al. 1986, Zhu and Wu 1990). That is, they are essentially based on a Taylor expansion of the equilibrium equations (static or dynamic) up to a low order (usually the second) and the application of averaging operators to the resulting expanded system. Numerical problems arise with secular terms where higher order moments than the second are of importance and the accuracy is restricted to those cases where the randomness of the field is small, as measured by its variance (Kleiber and Hein 1992). 
Another technique proposed is that of the Hierarchical Closure Approximation (Barucha - Reid 1968; Adomian 1983) in which the higher order moments of the system and the output are expressed as functions of lower order ones, in a similar way as it is done in the closure techniques of non linear random vibration (Muscolino 1993). Probably the most interesting analytical method developped in the last years is by far the Spectral Approach (Ghanem and Spanos 1991, 1997). This technique comprises the following steps:

a. A description of the random field by truncated infinite series using the Karhunen - Loeve decomposition (Papoulis 1991) which plays a role analog to that of the Fourier series analysis of deterministic signals.

b. Projection of the decomposed random field of the solution on a class of polynomials introduced by Wiener (1958) in his extension of Volterra's work on nonlinear systems and known as Homogeneous Chaoses (1989).

c. Solution of the resulting system of equations.

Other recent analytical approaches that deserve consideration are those due to Li and Der Kiureghian (1993) and Zhang and Ellingwood (1994).

Many of the developments of Monte Carlo techniques for analysis of random fields have been contributed by M. Shinozuka and his coworkers along the last three decades. The basic technique consists in taking advantage of the fact that the spectral density function of a harmonic process with variance $\sigma^{2}$ consists of a pair of Dirac pulses located in the respective frequency with intensity $\sigma^{2} / 2$. This means that in the one dimensional case the process
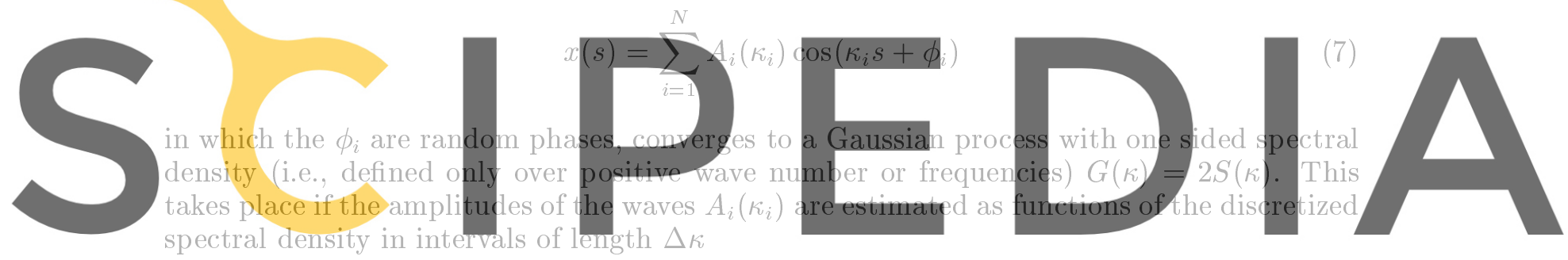

\section{Register for free at https//www.scipediaf.domvtefdionthload the version without the watermark}

due to the fact that the variance of the process is equal to the area under the curve of the spectral density. The extension of the formulation to higher dimensional processes is straightforward (Shinozuka and Lenoe, 1976; Vanmarcke et al. 1986; Shinozuka, 1987; Yamazaki and Shinozuka 1988). The simulation of the field is better accomplished by transforming the above equations to the complex space and applying the Fast Fourier Transform technique (Shinozuka and Lenoe 1976). In (Yamazaki and Shinozuka, 1988) the method is extended to non Gaussian fields. Finally, greater accuracy is obtained if the simulation is accomplished if a statistical preconditioning is exerted on the simulation (Yamazaki and Shinozuka 1990). In this respect the accuracy is defined as the approximation to the original correlation structure by that corresponding to the generated samples. This method, however, implies the Choleski decomposition of the covariance matrix of the field, a calculation that for large fields often found in FEM analysis becomes unwieldy. Nonhomogenity (also called nonstationarity in the theory of random processes) can be modelled by means of modulating functions of space and time (Shinozuka 1987c). Figure 7 shows an example of a simulated homogeneous random field.

A variant of the above FFT (Fast Fourier Trasform) technique has been proposed by Fenton (1990). The author criticizes the selection of the amplitudes of the harmonic function in the way of equation (8) since the random field will be bounded by the sum of the $A_{i}$ - a limitation that poses a constraint for reliability calculation. Also, it is demonstrated in that reference that the FFT method requires doubling the size of the random field in order to 


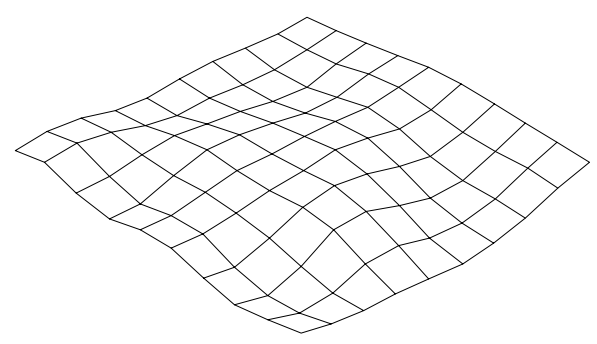

Figure 7. Simulated random field

obtain the same covariance structure given as datum to the generation. The same author had proposed in (Fenton and Vanmarcke 1990) a sampling method of random fields known as Local Average Subdivision which is based on the theory of local averages outlined above. The main disadvantages of this method are that, firstly, it itself is a mesh generator of a specif nature (rectangular elements of equal size) that puts it in conflict with the particular FE discretization requirements of each problem, and secondly, that it is more difficult to implement than the FFT procedure.

Other methods for simulating random fields are those proposed in two companion papers by (Mignolet and Spanos 1992; Spanos and Mignolet 1992) in which use made of the ARMA (Auto Regressive Moving Averages) procedures commonly used in the field of time series analysis (Priestley 1981); and the Turning Bands Method (Mantoglou and Wilson 1981) which generates two dimensional fields by simulating diagonal processes on arbitrary lines contained in the plane). Some methods devised in earthquake engineering for simulating random fields upon the (Kameda and Morikay example, a geometric application of the Krieg (Hoshiya 1994). It must.
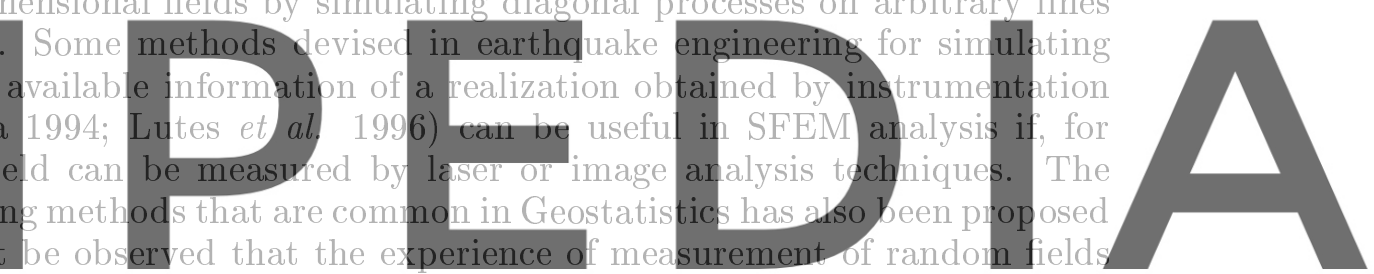
of material properties in structural engineering is quite limited as compared to that existing Register for free at https//www.scipedia.com to download the version without the watermark

\section{RELIABILITY ANALYSIS}

The expression Reliability Analysis is tobe understood as the calculation of the probability of failure of a random system subject to random conditions. The word failure is quite general since it is defined differently in each case. For example, one could define the failure of a structure as the region of deformation or stresses higher than some given critical values or as the ocurrence of any or both random events. In the first case we have a simple limit state function defined as

$$
G(\boldsymbol{x})=\bar{r}-r(\boldsymbol{x})
$$

where $\bar{r}$ is the critical value of the response $r(\boldsymbol{x})$ to the stochastic input $\boldsymbol{x}$ (basic variables). In the second or in more general cases we will have a limit state function defined by union $($ logical $\vee$ ) and intersections (logical $\wedge$ ) of different simple functions. In any case the failure and safe states are defined as follows:

- Safe state: $G(\boldsymbol{x})>0$

- Failure state: $G(\boldsymbol{x}) \leq 0$ 
The probability of failure will then be defined as the probability mass of the failure state:

$$
p_{\mathrm{f}}=\int_{\mathcal{R}} f(\boldsymbol{x}) \mathrm{d} \boldsymbol{x}
$$

where $f(\boldsymbol{x})$ is the joint probability density function of the basic variables and $\mathcal{R}$ is the region $G(\boldsymbol{x}) \leq 0$. In some cases a less sharp distinction between safe an failure states is defined by means of a transition function. But the usually low value of the probability of failure (of the order of $10^{-4}$ or lower) makes this sophistication unnecessary. It is clear that the feasibility of the analitycal calculation of this high dimensional integral is too restricted.

The most important analytical tools for calculating failure probabilities are known as First- and Second-order Reliability Methods (usually abreviated as FORM / SORM) of which abundant literature is available (see, for example, Melchers 1987). Both of them require the following steps:

\section{a. To transform the basic variables $\boldsymbol{X}$ into a set of standard normal variables $\boldsymbol{U}$. To do this the so called Rosenblatt transformation is used (Hohenblichler and Rackwitz 1979). It is important to observe thas this transformation implies no approximation of any kind. The transformation is performed by the following algorithm:}
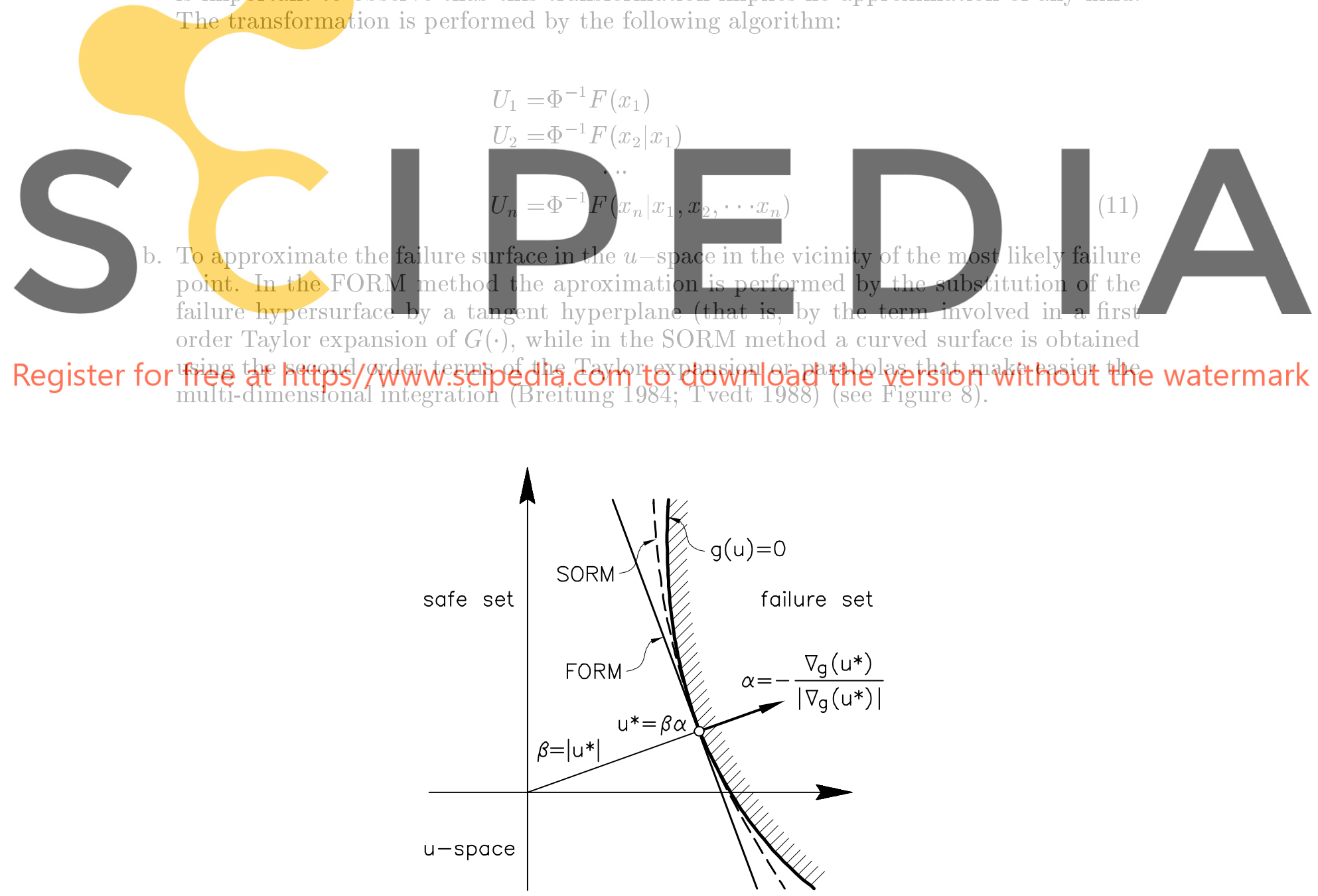

Figure 8. FORM/SORM methods 
c. To calculate the failure probaility. In the FORM case it is approximated by

$$
p_{\mathrm{f}}=\Phi(-\beta)
$$

where $\beta$ is the distance from the origin to the approximating hypersurface in the $U$-space; it is called the first order reliability index, since it measures how far the most critical point is located from the mean value of the random variables, as shown also in the figure. In the SORM analysis, the equation for estimating the failure probability depends on the selected approximating hypersurface.

The available Monte Carlo techniques for estimating the probability of failure can be grouped into two cathegories:

1. Those whose application depends on the limit state function $G(\boldsymbol{x})$

2. The opposite case.

In what follows these groups willl be examined in order.

\subsection{Methods dependent on the limit function}

An special and widely used application of Monte Carlo techniques is that of determining the value of a multidimensional definite integral. Suppose that the following integral is to be evaluated:

$$
p=\int I(\boldsymbol{x}) f(\boldsymbol{x}) \mathrm{d} \boldsymbol{x}
$$

Without loss of generality we can then regard $f(\cdot)$ as a density function so that an estimate of $p$ is given by

$$
\hat{p}=\frac{1}{n} \sum_{i=1}^{n} I\left(X_{i}\right)
$$

where the $n$ values $X_{i}$ have been sampled with density $f$. As a method of evaluating integrals the Monte Carlo method has the advantage that it is equally simple for one or for many dimensions. In the case at hand $f(\cdot)$ it is really a density function and $I(\cdot)$ is the indicator function

$$
I(\boldsymbol{x})= \begin{cases}1 & \text { if } G(\boldsymbol{x}) \leq 0 \\ 0 & \text { if } G(\boldsymbol{x})>0\end{cases}
$$

The application of the above mentioned Simple Random Sampling as the main Monte Carlo technique to the estimation of failure probabilities is in most cases quite inefficient. The reason is that while in other methods of numerical integration the variance of the estimators diminish as $n^{4}$ or even more rapidly, in the Monte Carlo method it does as $n$, with the consequence that a large number of samples is required to obtain a good estimator of the integral. In the case of structural reliability problems, where failure probabilities of very low order are usually expected, a rule of thumb is that an amount of approximately $100 / p_{\mathrm{f}}$ samples are required to get a good estimate of the integral using Simple Random Sampling. This magnitude is of course prohibitive for complex structural systems modelled by finite elements. 
The so called Variance Reduction Techniques have been devised to the purpose of increasing the efficiency of Monte Carlo integration (Rubinstein 1981; Bratley et al. 1987; Ripley 1987). In the following mention will be done of those Variance Reduction Techniques usually employed in the field of structural safety, which are Stratified Sampling, Importance Sampling and Antithetic Variates.

The conventional strategy of Sratified Sampling explained in the previous section must be modified when applied to the evaluation of mutidimensional integrals. As a matter of fact for simple statistical description it is enough to cover the whole space of the random variables by one or more samples that represent each rank of them. In the case of Monte Carlo Integration, the need of a variance reduction imposes a careful selection of the number of samples from each rank, in such a way that those contributing more to the whole variance must be more intensively sampled. The failure probability has to be calculated as

$$
\hat{p}_{\mathrm{f}}=\sum_{i}^{l} P_{i} \frac{1}{n_{i}} \sum_{j=1}^{n_{i}} I\left(X_{i}\right)
$$

where $n_{i}$ is the number of samples of each of the $l$ subregions in which the entire hypervolume has been divided, and $P_{i}$ is the probability mass of each subregion.

In the Importance Sampling technique the random variates are not obtained by means of the original multidimensional density function of the random variables but using an arbitrary density $g(\boldsymbol{x})$ which is concentrated in the critical region, that is, in the region that contributes most to the value of the failure probability, through the following conversion:

$$
p=\int I(\boldsymbol{x}) \frac{f(\boldsymbol{x})}{g(\boldsymbol{x})} g(\boldsymbol{x}) \mathrm{d} \boldsymbol{x}
$$

implying that the indicator function can be taken now as

$$
I(\boldsymbol{x})= \begin{cases}f(\boldsymbol{x}) / g(\boldsymbol{x}) & \text { if } G(\boldsymbol{x}) \leq 0 \\ 0 & \text { if } G(\boldsymbol{x})>0\end{cases}
$$

As sampling density the multivariate Gaussian is almost exclusively used. The main problem in this method lies in the selection of the appropiate mean vector and covariance matrix of this function. As a matter of fact the best position is that corresponding to the highest value of the density function on the limit state function (see Figure 9). But since in the case of complex structural systems this function is usually unknown in an explicit form, there exists always the possibility of locating the center of the sampling function $g$ somewhat far from that point, with the consequence that the sampling can be wrongly concentrated on the safe or in the failure regions. In (Ang et al. 1992) a method to overcome the arbitraryness in the selection of the importance sampling density is proposed, using the information of a previous simple random sampling. The optimal importance sampling density is built up by averaging windowed kernel densities whose parameters are obtained from the previous analysis. The importance sampling density has form

$$
g(\boldsymbol{x})=\frac{1}{M} \sum_{i=1}^{M} \frac{1}{w^{d}} K\left(\frac{\boldsymbol{x}-\boldsymbol{y}_{i}}{w}\right)
$$

where $M$ is the number of points obtained in the failure region in the first simple random sampling, $\boldsymbol{y}_{i}$ the corresponding samples, $w$ the window width and $K$ the kernel density, which as usual is taken to be the multivariate normal. Two different criteria for the estimation of the window width are suggested by the authors. The main objection that can be addressed to this method is, however, that at least one run of simple random sampling is required 


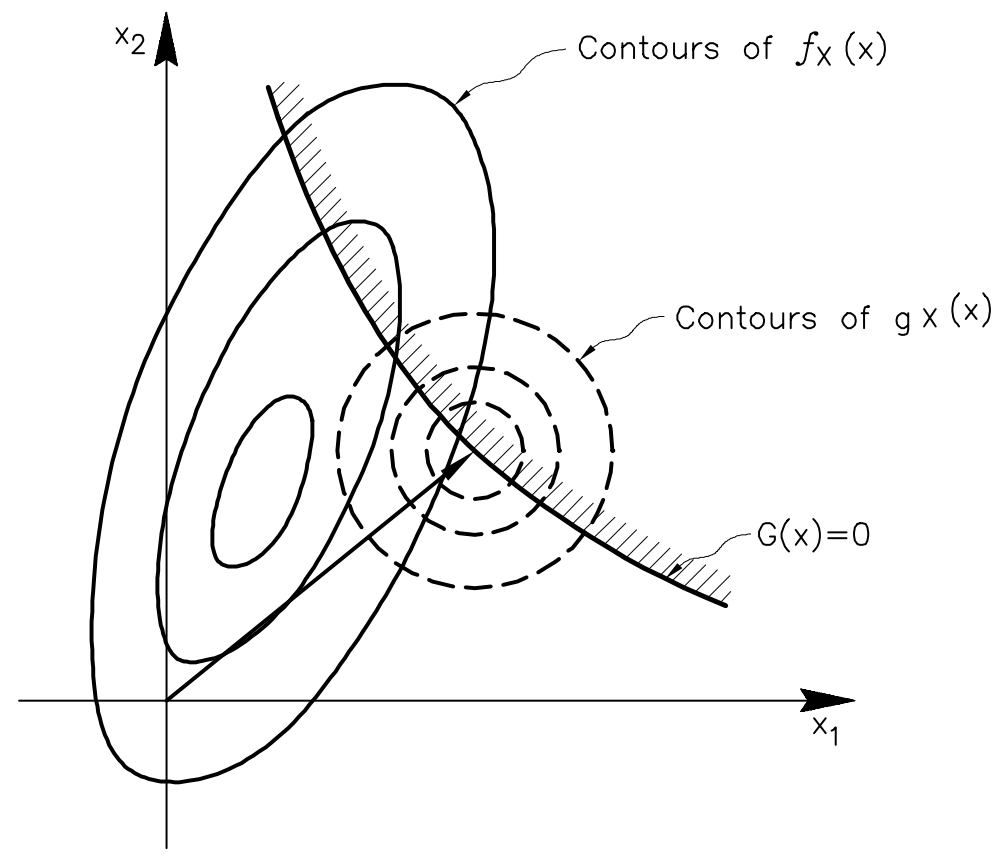

Figure 9. Importance Sampling

before its application, which in case of FE runs can amount to a large computational effort. An attempt to overcome this drawback of the method is proposed in (Wang and Ang 1994). In this version the kernel method is combined with the Adaptive Sampling concept (Bucher 1988), to be explained later, rather than with the Simple Random Sampling as it was in its original version. The resulting method is quite promising for the accurate calculation of failure probabilities.

On the other hand, in the case of multiple limite state functions, arising from several failure criteria, there is a need of more than one sampling density $g$ in different design points and the weighting of the results. The Figure 10 corresponds to a method proposed by Melchers (1987), in which the general sampling density $g$ is a linear combination of the individual sampling densities ${ }^{i} g$ of each of the $m$ design points:

$$
g(\boldsymbol{x})=\sum_{i=1}^{m}{a_{i}}^{i} g(\boldsymbol{x})
$$

where the $a_{i}$ are normalized weights evaluated on the basis of the distances to the design points from the origin in the normalized space. Another method proposed in (Schuëller and Stix 1987) proposes the weghting of the failure probabilities of each design points by means of the Gaussian probability associated to the corresponding reliability index $\beta$ of each of them.

The method of Antithetic Variates aims at the reduction of the variance of the estimator by a rather different way. Let $p_{1}$ and $p_{2}$ be two estimators of the integral. The estimator

$$
p_{\mathrm{f}}=\frac{p_{1}+p_{2}}{2}
$$

has the variance

$$
\operatorname{Var}\left(p_{\mathrm{f}}\right)=\frac{1}{4}\left(\operatorname{Var}\left(p_{1}\right)+\operatorname{Var}\left(p_{2}\right)+2 \operatorname{Cov}\left(p_{1}, p_{2}\right)\right)
$$




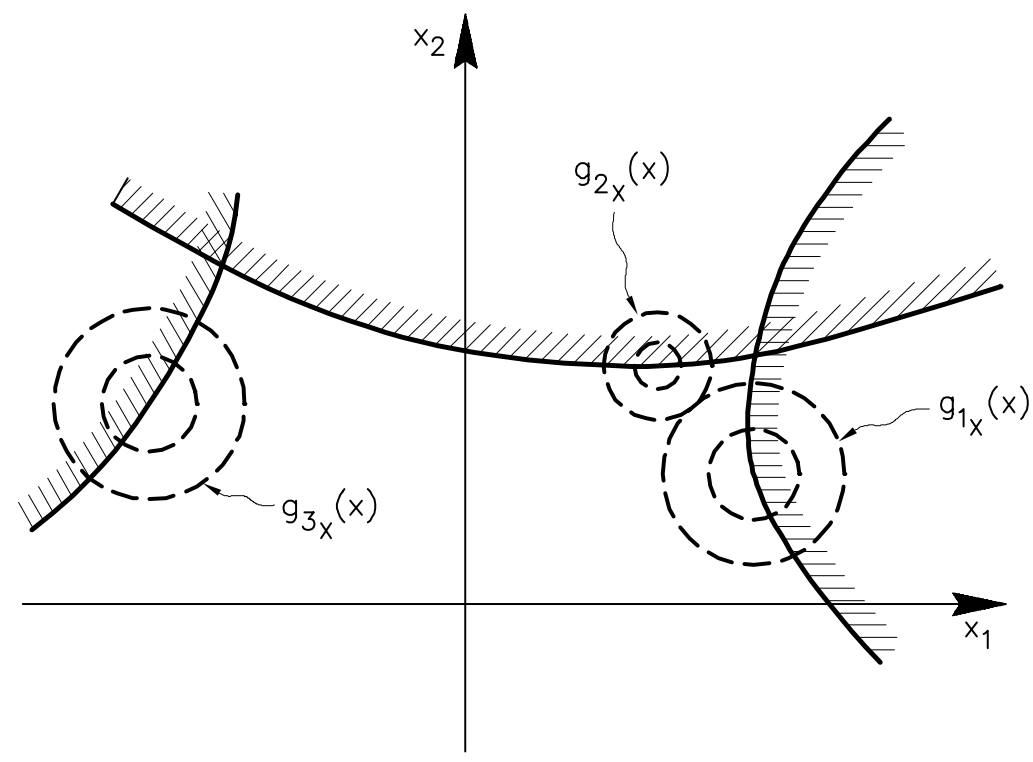

Figure 10. Importance Sampling for multiple failure modes

with the consequence that if $p_{1}$ and $p_{2}$ are negatively correlated a substantial reduction of the variance can be obtained by this method. The random variates of each variable $x_{i}$ can then be obtained using the inversion method. While the estimator $p_{1}$ is calculated using these random values based on uniform deviates $v_{i}$, the sample for $p_{2}$ is built up with the uniform variates $1-v_{i}$, which give by inversion the $x_{i}^{\prime}$ negatively correlated with $x_{i}$.

Under the name of Adaptive Sampling one can mention two techniques that perform variance reduction using iteratively the information gathered in previous steps. One of them (Bucher 1988; Schuëller et al. 1989) modifies the mean and covariance matrices of the Importance Sampling density (that is, its position and shape) after the statistics of the previous samples. The method is specially suitable for the analysis of systems with multiple failure modes. The second is the Vegas algorithm (Lepage 1980; Press et al. 1992) which looks for a separable importance sampling density, that is, a multidimensional function that can be expressed as the product of individual functions of each variable. In probabilistic terms this means to use a sampling density which is a multidimensional function of independent variables. This function is built up iteratively by using the information obtained in the previous runs. The method has been routinely applied in the field of particle physics since the last decade but, up to the authors' knowledge, there is no published experience of its use in structural reliability computations.

Other techniques employed for the assessment of failure probabilities can be grouped under the name of Conditional Simulation, because they use some known information about some of the random input variables inloved in the simulation. As an example, the Directional Simulation (Bjerager, 1988) (see Figure 11) the standard normal vector $\boldsymbol{u}$ is expressed as

$$
\boldsymbol{U}=r \boldsymbol{A}
$$

where $r^{2}$ plays the role of a radius and then has a chi-square distribution of $n$ degrees of freedom, and is independent of the unit random vector $\boldsymbol{A}$ which is uniformly distributed on the $n$-dimensional unit sphere. Linking this transformation with the Importance Sampling concept, as indicated in Figure 12, the indicator function is given in this case by

$$
I(\boldsymbol{a})= \begin{cases}f(\boldsymbol{a}) / g(\boldsymbol{a}) & \text { if } G(r \boldsymbol{a}) \leq 0 \\ 0 & \text { if } G(r \boldsymbol{a})>0\end{cases}
$$




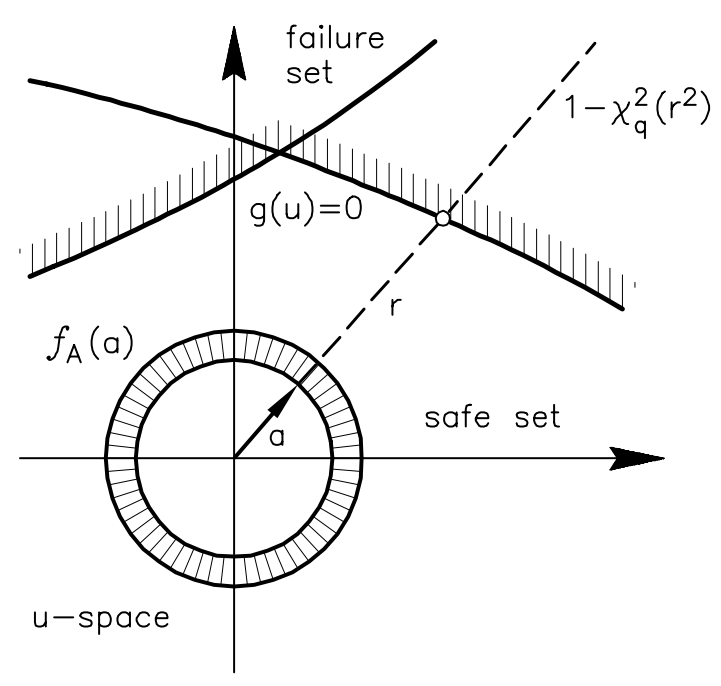

Figure 11. Directional Simulation

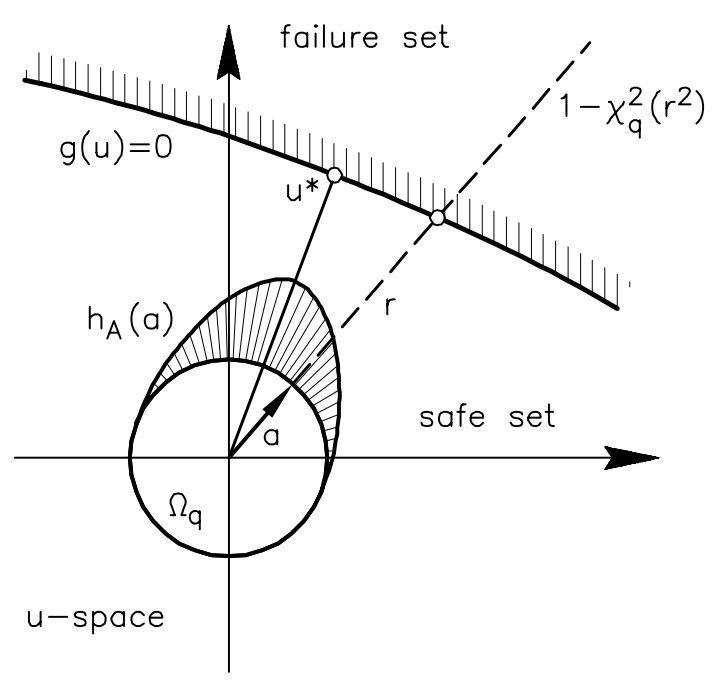

Figure 12. Directional Importance Sampling

Other techniques are the Axis-Orthogonal Simulation (Fujita and Rackwitz 1987) that is based on FORM/SORM results, and the Generalized Conditional Expectation (Ayyub and Haldar 1984; Ayyub and Chia 1992) in which the simulation is governed by a subset of the random variables having low dispersion. A recent improvement of this technique has been reported by (Shao and Murotsu 1994) by combining the traditional directional and adaptive importance sampling techniques.

The main criticisms that can be addressed to all the methods requiring the transformation of all the random variables to the standard normal space are that, first, the Rosenblatt transformation (Eq. 11) can be very involved in the case of a large number $n$ of random variables, and second, that there are in general $n$ ! ways to perform the transformation, so that in principle all of them must be considered to detect the critical one (Dolinsky 1983). 
This objection makes these methods useful only for improving the results calculated by analytical methods rather than for general analysis linked to an FE code. That is also the case of a rapidly convergent method for the iterative estimation of the Importance Sampling Density proposed by Yonesawa and Okuda (1994), which works only in the standard normal space.

\subsection{Methods not dependent on the limit function}

Unlike the above techniques, which obtain the samples for each particular set of limit state functions, modern statistical theory provides some tools which can be useful for estimating the probability of failure without reference to the basic variables. Therefore, the probabilities of a response are estimated on the basis of its own samples. Notice that is of great practical vaule, because of the following reasons: (a) One can model as that single response a variable collecting several failure modes using mathematical and logical operators such as $\min (\cdot), \max (\cdot), \vee$ or $\wedge$; (b) There is no need of recalculating the probabilites for a different set of critical values, since it is always possible to build up again the synthetic variable with the new thresholds on the available database. (c) The same database can be used for multiple realiability assessments. For example, contour maps of the probabilites of exceeding a some threshold stresses by each finite element can be esaily calculated by such expansions.

These techniques are, in general, expansions of the empirical density function of the response. The most important are

1. Cornish-Fisher expansion (Johnson et al. 1994)

2. Saddlepoint expansion (Kolassa 1997)

2. Edgeworth expansion (Hall 1992)

3. Normal expansion (Hong and Lind 1997)

Generally speaking, it can be stated that there is little experience in its use in structural analysis. In particular, no single reference has been found on structural applications of the second method, which has been developped in statistics just as a means of modeling the tails of an empirical density. The quoted recent paper by Hong and Lind (1997) compares the Cornish-Fisher and Normal expansions and recommends the use of the latter as a the most accurate of both. This is indeed a promising technique due to the above mentioned advantages.

Finally, some methods devised for sampling in the very low probability region of dynamic systems driven by white noise processes must be mentioned (Pradlwarter et al. 1994). In this procedure the importance sampling in the tails of the time - varying, multidimensional density function is mantained by doubling the state vectors of a high measure and clumping those of a low one. The measure used is that of the absorbed energy. In a more recent contribution (Pradlwarter and Schuëller 1995) the accuracy of the method is compared with that obtained with the less involved technique known as Russian Roulette and Splitting. Both methods succesfully conduct the sampling of rather low failure probabilities (of the order of $\left.10^{-7}\right)$. 


\section{RESPONSE SURFACE METHODS}

The last section of the present document is devoted to a brief description of the applications of a traditional statistical method that has gained acceptance in Stochastic Mechanics in the last years as a valuable tool for obtaining insight into the behavior of structural random systems at low costs. This is the Response Surface Method which was developped in the thirties and has been incorpored in the general field of experimental design of which abundant literature exists (see, for example, Box and Draper 1987). The main difference of the method with the Monte Carlo one is that the experiments are not random but rather carefully planned ones. The objective is to obtain a description of the influence of each variable and their possible combinations on the response of the system. The procedure contemplates the following steps: First of all, levels of value of each variable are defined; for example, four levels considered by the designer as very low, low, high and very high. Secondly, the responses of the system are obtained for selected combinations of them called treatments. The plan of the combination of the data is done according to different strategies. When the number of variables is equal to one, two or three the respective techniques are the Randomized Block Design, Latin Square and the Graeco-Latin Square. The most general technique is that of the Factorial Design in which all the combinations of the selected level values of the variables are combined with each other. A complete combination of all $d$ factors at two levels each would involve a total number of combinations equal to $2^{d}$. As a difference with respect the use of the experimental design used in laboratory tests, in numerical experimentation there is no need to randomize the order in which the experiments are done, because the "testing machine" in this case is not affected by previous analysis. Finally, since the total number of runs can be very high, and the effects of some of them can be indistinguishable from other ones, the number of analysis can be reduced by applying a Fractional Factorial Design of order $p$, thus giving a total number of replicates equal to $2^{d-p}$. The aim of this technique is to gain computational efficiency without losing important information.

The results of the analysis are processed to observe the so-called main effects, which are those primarily due to the variation of each input variable, and the two term interaction, three term interactions, etc., which play the role of higher order terms in the Taylor series expansions of a function (see Figure 13). This means that the selection of the $p$ degree of reduction is governed by the order of combinations that are expected to dominate the polynomial expression of the response surface.

The final step of the analysis is precisely the calculation of a first or (usually) second order regression of the response variables with respect to the input ones. Also it is important to calculate error and variance statistics which can help the analyst to improve the experimental design and take decisions about the system under analysis. The second order surface can be obtained by conventional least squares or by Bayesian analysis (Casciatti and Faravelli 1990). A second order surface such as that depicted in Figure 14 can then be represented by the expression

$$
\hat{y}=\beta_{0}+\sum_{i=1}^{d} \beta_{i} x_{i}+\sum_{i=1}^{d} \beta_{i i} x_{i}^{2}+\sum_{i=1}^{d} \sum_{j=1}^{i-1} \beta_{i j} x_{i} x_{j}
$$

The method has been applied in Reliability Analysis for calculating the limit state function and the failure probability using the fitted surface as a solver substitute (Bucher et al. 1991; Faravelli 1992; Enevoldsen et al. 1994; Kim and Na 1997). It has also been linked with random field techniques to incorpore the effects of time or spatial variation of the model parameters discussed previously (Casciatti and Faravelli 1990). 


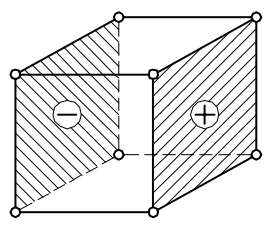

A

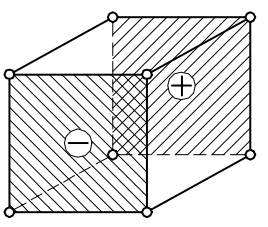

$\mathrm{B}$

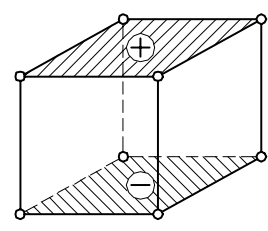

C

(a) Main effects

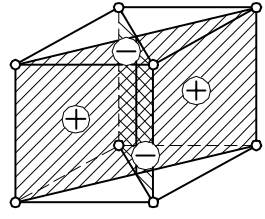

$\mathrm{AB}$

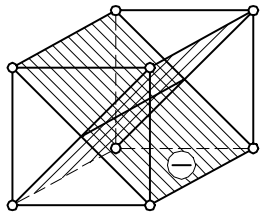

$\mathrm{AC}$

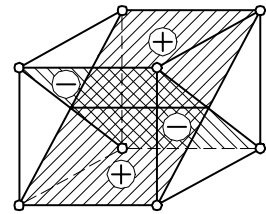

$\mathrm{BC}$

(b) Two-factor interactions

Figure 13. Fractional Factorial Design

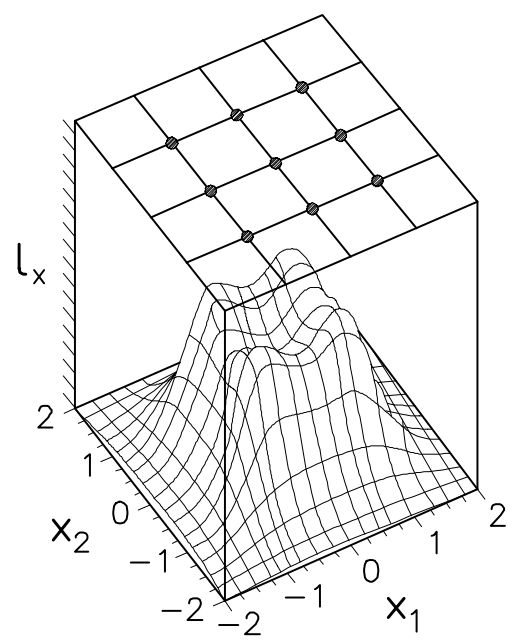

Figure 14. Response Surface

\section{CONCLUDING REMARKS}

The state of the knowledge in simulation methods for analysing the effects of uncertainties in structural mechanics has been summarized and discussed, after a review of a large number of references. Most of them concern the numerically difficult problem of Reliability Assessment, while only a few are devoted to the emerging area of research about the stochastic spatial variability of the structural parameters. This is an indirect reflect of the evolution of the interest of the scientific community along the last twenty years, which has been undoubtedly influenced by the rapid development in the computational resources, which nowadays allow to perform bigger Monte Carlo analyses whose cost was prohibitive in the recent past. 
Despite this progress, or perhaps as a consequence of it, new areas of research can be identified. Among them the following can be included:

1. Experimental measurement of the Random Field parameters of different materials for Stochastic Finite Element modelling, as well as some frequent correlations existing between different random variables tipically implied in structural models.

2. Stochastic Optimization of structures, that is, the development of techniques and criteria for performing structural optimization upon the constraint of matching prescribed failure probabilities.

\section{REFERENCES}

Adomian, G. (1983): Stochastic Systems, Academic Press, New York.

Ang, A. H. S., and Tang, W. H. (1984): Probability Concepts in Engineering Planning and Design, Vol II, John Wiley and Sons, New York.

Ang. G. L., Ang, A: H. S. and Tang, W. H. (1991): Optimal Importance Sampling Density Estimator, Journal of Engineering Mechanics, ASCE, 118(6), 1146-1163.

Araujo, J. M. and Awruch, A. M. (1994): On Stochastic Finite Elements for Structural Analysis, Computers and Structures, 52(3), 461-469.

Arnbjerg-Nielsen, T., and Bjerager, P. (1988): Finite Element Reliability Method with Improved Efficiency by Sensitivity Analysis, Computational Probabilistic Methods, ASME, AMD-Vol. 93, edited by Liu, Belytschko, Lawrence and Cruce, 15-25.

Augusti, G., Baratta, A., and Casciatti, F. (1984): Probabilistic Methods in Structural Engineering, Chapman and Hall, London.

Aumeier, S. E., Lee, J. C., Akcasu, A. Z. (1996): Probabilistic Techniques using Monte Carlo Sampling for Multi - component System Diagnostics, Proceedings of the International Conference on Mathematics and Computations, Reactor Physics annd Environmental Analyses, 103-112. La Grange Park.

Ayyub, B. M., and Haldar, A. (1984): Practical Structural Reliability Techniques, Journal of Engineering Mechanics, ASCE, 110(8), 1707-1724.

Ayyub, B. M., and Chia, C. Y. (1992): Generalized Conditional Expectation for Structural Reliability Assessment, Structural Safety, 11, 131-146.

Bazant, Z. P. and Liu, K. L. (1985): Random Creep and Shrinkage in Structures: Sampling, Journal of Structural Engineering, ASCE, 111(5), 1113-1134.

Bharucha - Reid, A. T. (1959): On Random Operator Equations in Banach Space, Bull. Acad. Polon. Sci., Ser. Sci. Math. Astr. Phys., Vol. 7, 561-564.

Bjerager, P., and Krenk, S. (1987): Sensitivity Measures in Structural Reliability Analysis, Proc. of 1st IFIP Working Conference on Reliability and Optimization on Structural Systems, edited by P. Thoft-Christensen, Springer Verlag, 459-470.

Bjerager, P. (1988): Probability Integration by Directional Simulation, Journal of Engineering Mechanics, ASCE, 114(8), 1285-1302.

Bjerager, P. (1991): Methods for Structural Reliability Computations, in Reliability Problems: General Principles and Applications in Mechanics of Solids and Structures, edited by Casciatti, F. and Roberts, J. B., Springer-Verlag, New York.

Box, G. E. P., and Draper, N. R. (1987): Empirical Model-Building and Response Surfaces, John Wiley and Sons, New York. 
Bratley, P., Fox, B. L., Schrage, L. E. (1987): A Guide to Simulation, Springer Verlag, New York.

Breitung, K. (1984): Asymptotic Approximation for Multinormal Integrals, Journal of Engineering Mechanics, ASCE, 110(3), 357-366.

Brenner, Ch. E., and Bucher, Ch. (1995): A contribution to the SFE-based Reliability Assessment of Nonlinear Structures Under Dynamic Loading, Probabilistic Engineering Mechanics, 10, 265-273.

Bucher, C. G. (1988): Adaptive Sampling: An Iterative Fast Monte-Carlo Procedure, Structural Safety, 5(2), 119-126.

Bucher, C. G., Pradlwarter, H. J. and Schuëller, G. I. (1991): Computational Stochastic Structural Analysis (COSSAN), Structural Dynamics: Recent Advances (G. I. Schuëller, editor). Springer Verlag, Berlin.

Bucher, C. G., Brenner, C. E. (1992): Stochastic Response of Uncertain Systems, Archive of applied Mechanics, 62(8), 507-516.

Casciatti, F. and Faravelli, L. (1990) Fragility Analysis of Complex Structural Systems Research Studies Press Ltd., Taunton, England.

Casciatti, F. (1991): Safety Index, Stochastic Finite Elements and Expert Systems, in Reliability Problems: General Principles and Applications in Mechanics of Solids and Structures, edited by Casciatti, F. and Roberts, J. B., Springer-Verlag, New York.

Chang, T. P., Chang, H. C. (1994): Stochastic Dynamic Finite Element Analysis of a Non Uniform Beam, International Journal of Solids and Structures, 3195), 587-597.

Chinchalkar, S., Taylor, D. L. (1991): Parallel Stochastic Finite Element Analysis on Distributed Memory Multiprocessors, in High Performance Computing, II, 345-356, North Holland, Amsterdam.

Cruse, T. A., Wu, Y. T., Dias, S., and Rajagopal, K. R. (1988): Probabilistic Structural Analysis Methods and Applications, Computers and Structures, 30(1/2), 163-170.

Der Kiureghian, A. (1985): Finite Element Based Reliability Analysis of Frame Structures, Structural Safety and Reliability, edited by Konishi, Ang and Shinozuka, ICOSSAR, Kobe, Japan, Vol.I., 395404.

Der Kiureghian, A., and Liu, P. L. (1986): Structural Reliability under Incomplete Probability Information, Journal of Engineering Mechanics, ASCE, 112(1), 85-104.

Der Kiureghian, A., and Lin, H. Z., and Hwang, S.J. (1987): Second Order Reliability Approximations. Journal of Engineering Mechanics, ASCE, 113(8), 1208-1225.

Der Kiureghian, A., and Ke, J. B. (1987): The Stochastic Finite Element Method in Structural Reliability, Probabilistic Engineering Mechanics, 3(2), 83-91.

Der Kiureghian, A. (1988): Measures of Structural Safety under Imperfect States of Knowledge, Journal of structural Engineering, ASCE.

Der Kiureghian, A. and Ke, J. B. (1988): The Stochastic Finite Element Method in Structural Reliability, Probabilistic Engineering Mechanics, 3(2). 83-91.

Der Kiureghian, A., and De Stefano, M. (1990): An Efficient Algorithm for Second-Order Reliability Analysis, Report No. UCB 90/20, Department of Civil Engineering, University of California at Berkeley, Berkeley, California.

Ditlevsen, O., and Bjerager, P. (1986): Methods of Structural Systems Reliability, Structural Safety, $3,195-229$.

Ditlevsen, O., Bjerager, P., Olesen, R., and Hasofer, A:M. (1988): Directional Simulation in Gaussian Processes, Probabilistic Engineering Mechanics, 3(4), 207-217. 
Dolinski, K. (1983): First-Order Second Moment Approximation in Reliability of Structural Systems: Critical Review and Alternative Approach, Structural Safety, 1, 211-231.

Enevoldsen, I., Faber, M. H., and Sorensen, J. D. (1994): Adaptive Response Surface Techniques in Reliability Estimation, Structural Safety and Reliability, ed by Schuëller, Shinozuka and Yao, Balkema, Rotterdam, 1257-1264.

Enevoldsen, I., Faber, M. H., and Sorensen, J. D. (1994): Adaptive Response Surface Techniques in Reliability Estimation. Structural Safety and Reliability. II, 1257-1265. Balkema, Rotterdam.

Faber, M., and Rackwitz, R. (1988): Excursion Probabilities of Non - Homogeneous Gaussian Scalar Fields based on Maxima Considerations, Proc. of 2nd IFIP Working Conference on Reliability and Optimization on Structural Systems, edited by P. Thoft-Christensen, Springer Verlag .

Faravelli, L. (1988): Stochastic Finite Elements by Response Surface Techniques in Computational Probabilistic Methods, ASME-AMD, VOL. 93, 197-203.

Faravelli, L. (1989): Response Surface Approach for Reliability Analysis, Journal of Engineering Mechanics, ASCE, 115(12), 2763-2781.

Faravelli, L., and Bigi, D.(1990): Stochastic Finite Elements for Crash Problems, Structural Safety, $8,113-130$.

Faravelli, L. (1993): Dynamic Analysis of Complex Structural Systems, in Dynamic Motion Chaotic and Stochastic Behaviour, edited by Casciatti, Springer Verlag, New York.

Faravelli, L. (1993): Dynamic Analysis of Complex Structural Systems, in: Dynamic Motion. Chaotic and Stochastic Behavior. (F. Casciatti, editor), 301-324, Springer Verlag, Wien.

Fenton, G. A. (1994): Error Evaluation of Three Random-Field Generators, Journal of Engineering Mechanics, ASCE, 120(12), 2478-2497.

Fenton, G. A., and Vanmarcke, E. H. (1990): Simulation of Random Fields via Local Average Subdivision, Journal of Engineering Mechanics, ASCE, 116(8), 1733-1949.

Fiessler, B., Neumann, H.J., and Rackwitz, R. (1979): Quadratic Limit States in Structural Reliability, Journal of Engineering Mechanics Division, ASCE, 105, 661-676.

Florian, A. (1992): An Efficient Sampling Scheme: Updated Latin Hypercube Sampling, Probabilistic Engineering Mechanics, 7, 123-130.

Fujita, M., and Rackwitz, R. (1988): Updating First and Second Order Reliability Estimates by Importance Sampling, Structural Engineering and Earthquake Engineering, JSCE, 5(1), 31s-37s.

Fujita, M., Schall, G. and Rackwitz, R. (1987): Time Variant Component Reliabilities by FORM and SORM and Updating by Importance Sampling, Proc. of ICASP 5, Vancouver, Vol. 2, 520-527.

Ghanem, R. G. and Spanos, P. D. (1991): Stochastic Finite Elements: A Spectral Approach, Springer Verlag, New York.

Ghanem, R. G. and Spanos, P. D. (1997): Spectral Techniques for Stochastic Finite Elements, Archives of Computational Methods in Engineering, 4(10 63-100.

Gollwitzer, S., Zverev, A., Cuntze, R. and Grimmelt, M. (1994): Structural Reliability Applications in Aerospace Engineering. Structural Safety and Reliability. II, 1265-1272. Balkema, Rotterdam.

Gollwitzer, S., and Rackwitz, R. (1988): An Efficient Numerical Solution to the Multinormal Integral, Probabilistic Engineering Mechanics, 3(2), 98-101.

Guoliang, J., Lin, C., Jiamei, D. (1993): Monte Carlo Finite Element Mothod of Structure Reliability Analysis, Reliability Engineering and System Safety, 40(1), 77-83. 
Hall, P. (1992): The Bootstrap and the Edgeworth Expansion Springer-Verlag, New York.

Harbitz, A. (1983): Efficient and Accurate Probability of Failure Calculation by use of the Importance Sampling Technique. Proc. of ICASP4, Firenze, Italy, 825-836.

Harbitz, A. (1986): An Efficient Sampling Method for Probability of Failure Calculation, Structural Safety, 3, 109-115.

Hasofer, A. M., and Lind, N. C. (1974): Exact and Invariant Second Moment Code Format. Journal of the Engineering Mechanics Division, ASCE, 100(EM1), 111-121.

Hasselman, T. K. and Hart, G. C. (1972): Modal Analysis of Random Structural Systems, Journal of Engineering Mechanics, ASCE, 98(EM3), 561-579.

Hisada, T. and Nakagiri, S. (1985): Role of the Stochastic Finite Element Method in Structural Safety and Reliability, ICOSSAR '85, International Conference on Structural Safety and Reliability, I, 385-392.

Hohenbichler, M., and Rackwitz, R. (1981): Non normal Dependent Vectors in Structural Reliability, Journal of Engineering Mechanics Division, ASCE, 107, 1227-1238.

Hohenbichler, M., and Rackwitz, R. (1986a): Sensitivity and Importance Measures in Structural Reliability, Civil Engineering Systems, 3(4), 203-209.

Hohenbichler, M., and Rackwitz, R. (1986b): Asymptotic Crossing Rate of Gaussian Vector Processes into Intersections of Failure Domains, Probabilistic Engineering Mechanics, I(3), 177-179.

Hohenbichler, M., Gollwitzer, S., Kruse, W., and Rackwitz, R.: New Light on First-and SecondOrder Reliability Methods, Structural Safety, 4, 267-284.

Hohenbichler, M., and Rackwitz, R. (1988): Improvement of Second Order Reliability Estimates by Importance Sampling, Journal of Engineering Mechanics, ASCE, 114(12), 2195-2199.

Hong, H. P. and Lind, N. C. (1996): Approximate reliability analysis using normal polynomial and simulation results, Structural Safety, 18:329-339.

Hoshiya, M. (1994): Conditional Simulation of a Stochastic Field. Structural Safety and Reliability. I, 349-354. Balkema, Rotterdam.

Igusa, T., and Der Kiureghian, A. (1988): Response of Uncertain Systems to Stochastic Excitation, Journal of Engineering Mechanics, ASCE, 114(5).

Iman R. L. and Canover, W. J. (1980): Small Sample Sensitivity Analysis Techniques for Computer Models with an Application to Risk Assessment, Communications in Statistics, Theory and Methods, A9(17), 1749-1842.

Johnson, N. L., S. Kotz and N. Balakrishnan (1994): Continuous Univariate Distributions, 2nd. edition. John Wiley, New York.

Kameda, H. and Morikawa, H. (1994): Conditional Stochastic Processes for Conditional Random Fields, Journal of Engineering Mechanics, ASCE, 120(4), 855-875.

Karamchandani, A. (1987): Structural System Reliability Analysis Methods, Report 83, John A. Blume Earthquake Engineering Center, Stanford University.

Karamchandani, A., Bjerager, P., and Cornell, C. A. (1988): Methods to Estimate Parametric Sensitivity in Structural Reliability Analysis, Probabilistic Engineering Mechanics, ASCE, edited by P.D. Spanos, 86-89.

Karamchandani, A., Bjerager, P., and Cornell, C. A. (1989): Adaptive Importance Sampling, Proceedings, 5th International Conference on Structural Safety and Reliability, San Francisco, California, August 7-11, 1989. 
Kasutki, S. and Frogonpol, D. M. (1994): Hypersphere Division Method for Structural Reliability, Journal of Engineering Mechanics, ASCE, 120(11), 2405-2442.

Kim, S. H. and Na, S. W. (1997): Response Surface Method using Vector Projected Sampling Points. Structural Safety, 19:3-19.

Kleiber, M. and Hien, T. D.( 1992), The Stochastic Finite Element Method John Wiley and Sons, New York.

Kolassa, J. E. (1997): Series Approximation Methods in Statistics, 2nd. edition. Springer-Verlag, New York.

Law, A. and Kelton, W. D. (1991): Simulation Modeing and Analysis, McGraw Hill, Singapore.

Lepage, G. P. (1980): VEGAS: An Adaptive Multidimensional Integration Program. Publication CLNS-80/447. Cornell University.

Li, C. C. and Der Kiureghian, A. (1993): Optimal Discretization of Random Fields, Journal of Engineering Mechanics, ASCE, 119 (6), 1136-1154.

Li, Y. and Kareem, A. (1993): Simulation of Multivariate Random Processes: Hybrid DFT and Digital Filtering Approach, Journal of Engineering Mechanics, 119(5), 1078-1098.

Lin, H. Z., and Der Kiureghian, A. (1987): Second-Order System Reliability using Directional Simulation, Reliability and Risk Analysis in civil Engineering 2, ICASP5. edited by N.C. Lind, University of Waterloo, Ontario Canada, 930-936.

Liu, P. L., and Der Kiureghian, A. (1988a): Reliability of Geometrically Nonlinear Structures, Probabilistic Engineering Mechanics, ASCE, edited by P.D. Spanos, 164-167.

Liu, P. L., and Der Kiureghian, A. (1988b): Optimization Algorithms for Structural Reliability, Computational Probabilistic Methods, ASCE, 93, edited by Liu, Belytschko, Lawrence and Cruce, 185-196.

Liu, P. L. (1993): Selection of Random Field Mesh in Finite Element Reliability Analysis, Journal of Engineering Mechanics, ASCE, 119(4), 667-680.

Liu, W. K., Belytschko, T., and Mani, A. (1986): Random Field Finite Elements , Numerical Methods in Engineering, 23, 1831-1845.

Liu, W. K., Mani, A., and Belytschko, T. (1987): Finite Element Methods in Probabilistic Mechanics, Probabilistic Engineering Mechanics, 2(4), 201-213.

Liu, W. K., Besterfield, G. H. and Belytschko, T. (1988): Variational Approach to Probabilistic finite Elements, Journal of Engineering Mechanics, ASCE, 114(12), 2115-2133.

Lutes, L. D., Shahram, S., and Jin, S. (1996): Efficiency and Accuracy in Simulation of random Fields, Probabilistic Engineering Mechanics, 11, 73-86.

Madsen, H. O., Krenk, S. and Lind, N. C. (1986): Methods of Structural Safety, Prentice-Hall, Inc., Englewood Cliffs, N. J.

Madsen, H. O. (1987): Model Updating in Reliability Theory, Reliability and Risk Analysis in Civil Engineering 1, ICASP 5, edited by N. C. Lind, University of Waterloo, Ontario, Canada, 564-577.

Madsen, H. O. and Moghtaderi-Zadeh, M. (1987): Reliability of Plates under Combined Loading, Proceedings, Marine Structural Reliability Symposium, SNAME, Arlington, Virginia, 185-191.

Madsen, H. O., and Tvedt, L. (1988): Efficient Methods in Time Dependent Reliability, Probabilistic Engineering Mechanics, ASCE, edited by P. D. Spanos, 432-435.

Madsen, H. O.(1988): Omission Sensitivity Factors, Structual Safety, 5, 35-45. 
Madsen, H. O. and Tvedt, L. (1990): Methods for Time-Dependent Reliability and Sensitivity Analysis, Journal of Engineering Mechanics, ASCE, 116(10), 2118-2135.

Maltz, F. H. and Hitzl, D. L. (1979): Variance Reduction in Monte-Carlo Computations Using Multi-Dimensional Hermite Polynomials, Journal of Computational Physics, 32, 345-376.

Mantoglou, A. and Wilson, J. L. (1981): Simulation of Random Fields with the Turning Bands Method, Rep. No 264, Deptartment of Civil Engineering, MIT, Cambridge, Mass.

Marek, P., Gustar, M. and Anagnos, T. (1996): Simulation - Based Reliability Assessment for Structural Engineers. CRC Press, Boca Raton.

McKay, M. D., Beckman, R. J. and Conover, W. J. (1979): A Comparison of Three Methods for Selecting Values of input Variables in the Analysis of Output from a Computer Code, Technometrics, $21(2)$.

Melchers, R. E. (1987): Structural Reliability, Analysis and Prediction, Ellis Horwood Series in Civil Engineering, Halsted Press, England.

Melchers, R. E. (1994): Structural System Reliability Assessment Using Directional Simulation, Structural Safety, 16, 23-37.

Mignolet, M. P. and Spanos, P. D. (1992): Simulation of Homogeneous Two-Dimensional Random Fields: Part I-AR and ARMA Models, Journal of Applied Mechanics, 59, S260-S269.

Muscolino, G. (1993): Response of Linear and Non-linear Structural Systems under Gaussian or Non-Gaussian Filtered Input, in: Dynamic Motion. Chaotic and Stochastic Behavior. (edited by F. Casciatti), 203-301, Springer Verlag, Wien.

Nakagiri, S. and Hisada, T. (1982): Stochastic Finite Element Method Applied to Structural Analysis with Uncertain Parameters, Proceedings of the International Conference on FEM, 206-211.

Nataf, A. (1962): Determination des distributions dont les marges sont donées. Comptes rendues de l'Academie des Sciences, Paris, 225, 42-43.

Paloheimo, E. and Hannus, M. (1974): Structural Design Based on Weighted Fractiles, Journal of the Structural Division, ASCE, 100(ST7), 1367-1378.

Papadopoulos, V. and Papadrakakis, M., (1996): Efficient Solution Procedures for the Stochastic Analysis of Space Frames using the Monte Carlo Simulation. Developments in Computational Techniques for Structural Engineering (edited by Topping, B. H. V.), 61-70, Edinburgh.

Papoulis, A. (1991): Probability, Random Variables and Stochastic Processes, McGraw Hill, New York.

Plantec, J. Y. and Rackwitz, R. (1989): Structural Reliability under Non-Stationary Gaussian Vector Process Loads, Proceedings of the Eighth International Conference on Offshore Mechanics and Arctic Engineering, The Hague, The Netherlands, 1989.

Ponslet, E., Maglaras, G., Haftka, R. T., Nikolaidis, E., and Sensharma, P. (1994): Analytical and Experimental Comparison of Probabilistic and Deterministic Optimization, American Institute of Aeronautics and Astronautics, 544-559.

Pulido, J. E., Jacobs, T. L., and Prates de Lima, E. C. (1992): Structural Reliability using Monte Carlo Simulation with Variance Reduction Techniques on Elastic - Plastic Structures, Computers and Structures, 43(3), 419-430.

Pradlwarter, H. J. and Schuëller, G. I. and Melnik-Melnikov, P. G. (1994): Reliability of MDOFSystems, Probabilistic Engineering Mechanics, 9, 235-243.

Pradlwarter, H. J. and Schuëller, G. I. (1995): On Advanced Monte Carlo Simulation Procedures in Stochastic Structural Dynamics, Submitted to: Journal of Nonlinear Mechanics. 
Press, W. H., Teukolsky, S. A., Vetterling, W. T. and Flannery, B. P. (1992): Numerical Recipes in FORTRAN, Cambridge University Press, Cambridge.

Priestley, M. B. (1994): Spectral Analysis and Time Series, Academic Press, London.

Rackwitz, R. (1982): Response Surfaces in Structural Reliability, Report 67, 1982, Institut fur Bauingenieurwesen III, Technical University of Munich, West Germany.

Righetti, G. and Harrop-Williams, K. (1988): Finite Element Analysis of Random Soil Media, Journal of Geotechnical Engineering, 114(1), 59-75.

Ripley, B. D. (1987): Stochastic Simulation, John Wiley and Sons, New York.

Ronold, K. O. (1989): Probabilistic Consolidation Analysis with Model Updating, Journal of Geotechnical Engineering, ASCE, 115(2).

Rubinstein, R. Y. (1981): Simulation and the Montecarlo Method, J. Wiley and Sons, New York.

Santos, J. L. T., Siemaszko, A., Cardoso, J. M. B., and Barros, P. M. S. (1994): Interactive-Computer Aided Reliability Engineering, American Institute of Aeronautics and Astronautics, 581-589.

Schetzen, M. (1989): The Volterra and Wiener Theories and Nonlinear Systems. Krieger Publishing Company, Malabar, Florida.

Schuëller, G. I. and Shinozuka, M. (eds.) (1987): Stochastic Methods in Structural Dynamics. Martinus Nijhoff Publishers, Dordrecht.

Schuëller, G. I. and Stix, R. (1987): A Critical Appraisal of Methods to determine Failure Probabilities, Structural Safety, 4, 293-309.

Schuëller, G. I., Bucher, C. G., Bourgund, U. and Ouypornprasert, W. (1989): On Efficient Computational Schemes to Calculate Structural Failure Probabilities, Probabilistic Engineering Mechanics, $4(1), 10-18$.

Schuëller, G. I., Bucher, C. G., and Pradlwarter, H. J. (1990): Computational Methods in Stochastic Structural Dynamics, Structural Dynamics, ed by Krätzig et al., 599-636.

Schuëller, G. I. and Bayer, V. (1996): Computational Procedures in Structural Reliability. Proceedings of the Second International Symposium on Uncertainty Modelling and Analysis, 152-159, IEEE Computers Society Press.

Shao S. and Murotsu, Y. (1994): Reliability of Complex Structural Systems using an Efficient Directional Simulation. Structural Safety and Reliability. III, 1529-1534. Balkema, Rotterdam.

Shinozuka, M. (1964): Probability of Failure under Random Loading, Journal of Engineering Mechanics, ASCE, 90(5), 147-171.

Shinozuka, M. and Lenoe, R. (1976): A Probabilistic Model for Spatial Distribution of Material Properties, Engineering Fracture Mechanics, 8, 217-227.

Shinozuka, M. (1983): Basic Analysis of Structural Safety, Journal of Structural Engineering, ASCE, 109(3), 721-740.

Shinozuka, M. (1987a): Structural Response Variability, Journal of Engineering Mechanics, ASCE, $113(6), 825-842$.

Shinozuka, M. (1987b): Basic Issues in Stochastic Finite Element Analysis, Reliability and Risk Analysis in Civil Engineering, 1, edited by N. C. Lind, University of Waterloo, Ontario, 506-519.

Shinozuka, M. (1987c): Stochastic Fields and Their Digital Simulation, in Stochastic Methods in Structural Dynamics, edited by Schuëller, G. I. and Shinozuka, M., Martinus Nijhoff Publishers, Dordrecht. 
Spanos, P. D. and Mignolet, M. P. (1992): Simulation of Homogeneous Two-Dimensional Random Fields: Part II - MA and ARMA Models, Journal of Applied Mechanics, 59, 270-277.

Spanos, P. D., and Zeldin, B. A. (1994): Galerkin Sampling Method for Stochastic Mechanics Problems, Journal of Engineering Mechanics, ASCE, 120(5), 1091-1106.

Stubbs, N., Kim, J. T. and Topole, K. G. (1994): Experimental Determination of System Stochasticity. Structural Safety and Reliability. I, 369-374. Balkema, Rotterdam.

Thoft-Christensen, P. and Murotsu, Y. (1986): Application of Structural Systems Reliability Theory, Springer Verlag, West Germany.

Turk, G., Ramirez, M. R. and Corotis, R. B. (1994): Structural Reliability Analysis of Nonlinear Systems, Structural Safety and Reliability, ed by Schuëller, Shinozuka and Yao, Balkema, Rotterdam, 1345-1352.

Tvedt, L. (1988): Second Order Reliability by an Exact Integral, Proc. of 2nd IFIP Working Conference on Reliability and Optimization on Structural Systems, edited by P. Thoft-Christensen, Springer Verlag (in press).

Vanmarcke, E. (1983): Random Fields: Analysis and Synthesis, M.I.T. Press, Cambridge.

Vanmarcke, E., Shinozuka, M. Nakagiri, S. Schuëller, G. I. and Grigoriu, M. (1986): Random Fields and Stochastic Finite Elements, Structural Safety, 3, 143-166.

Vanmarcke, E. (1994): Stochastic finite elements and experimental measurements. Probabilistic Engineering Mechanics, 9, 103-114.

Van Vinckenroy, G., De Wilde, W. P. (1993): Monte Carlo Techniques applied to Finite Element Modelling of Adhesively Bonded Joints, Computational Methods and Experimental Measurements (edited by C. A. Brebbia and G. M. Carlomagno), 2, 3-12.

Veneziano, D., Casciatti, F. and Faravelli, L. (1983): Method of Seismic Fragility for Complicated Systems, Proceedings of 2nd Commitee on the Safety of Nuclear installations (CSNI): Specialist Meeting on Probabilistic Methods in Seismic Risk Assessment for NPP, Livermore, California.

Wang, G. S., and Ang, A. H. S. (1994): Adaptive Kernel Method for Evaluating Structural System Reliability. Structural Safety and Reliability. III, 1495-1500. Balkema, Rotterdam.

Wen, Y. K. (1987): Approximate Methods for Nonlinear Time-Variant Reliability Analysis, Journal of Engineering Mechanics, ASCE, 113(12), 1826-1839.

Wen, Y. K. and Chen, H. C. (1987): On Fast Integration for Time Variant Structural Reliability, Probabilistic Engineering Mechanics, 2(3), 156-162.

Wiener, N. (1958):Nonlinear Problems in Random Theory, Technology Press of the Massachussets Institute of Technology and John Wiley and Sons Inc., New York.

Winkler, G. (1995): Image Analysis, Random Fields and Dynamic Monte Carlo Methods. Springer Verlag, Berlin.

Winterstein, S. R. and Cornell C. A. (1984): Load Combination and Clustering Effects, Journal of Structural Engineering, ASCE, 110, 2690-2708.

Winterstein, S. R. and Bjerager, P. (1987): The Use of Higher Moments in Reliability Estimation, Reliability and Risk Analysis in Civil Engineering 2, ICASP 5, edited by N. C. Lind, University of Waterloo, Ontario, Canada, 1027-1036.

Winterstein, S. R. (1988): Nonlinear Vibration Models for Extremes and Fatigue, Journal of Engineering Mechanics, ASCE, 114(10), 1772-1790.

Wirsching, P. H., Ortiz, K., and Lee, S. J. (1987): An Overview of Reliability Methods in Mechanical and Structural Desing, American Institute of Aeronautics and Astronautics, 260-266. 
Wu, Y. T. and Wirsching, P. H. (1987): A New Algorithm for Structural Reliability Estimation, Journal of Engineering Mechanics, ASCE, 113, 1319-1336.

Wu, Y. T., Burnside, O. H. and Cruse, T. A. (1989): Probabilistic Methods for Structural Response Analysis, Computational Mechanics of Probabilistic and Reliability Analysis, edited by Liu and Belytschko, Elme Press International, Lausanne, Switzerland.

Yamazaki, F. and Shinozuka, M. (1986): Digital Generation of Non-Gaussian Stochastic Fields, Technical Report, Department of Civil Engineering, Columbia University, New York.

Yamazaki, F. and Shinozuka, M. (1988): Digital Generation of Non-Gaussian Stochastic Fields, Journal of Engineering Mechanics, ASCE, 114(7), 1183-1197.

Yamazaki, F., Shinozuka, M. and Dasgupta, G. (1988): Neumann Expansion for Stochastic Finite Element Analysis, Journal of Engineering Mechanics, ASCE, 114(8), 1335-1354.

Yamazaki, F. (1990): Simulation of Stochastic Fields by Statistical Preconditioning, Journal of Engineering Mechanics, ASCE, 116(2), 268-287.

Yamazaki, F., and Shinozuka, M. (1990): Simulation of Stochastic Fields by Statistical Preconditioning, Journal of Engineering Mechanics, ASCE, 116(2), 268-287.

Yonezawa, M. and Okuda, S. (1994): An Improved Importance Sampling Density Estimation for Structural Reliability Assessment, in Structural Safety and Reliability, ICOSSAR '93, 3, 1501-1508. edited by Schuëller, G. I., Shinozuka, M. and Yao, J. T. P., A. A. Balkema, Rotterdam.

Zhang, J. and Ellingwood, B. (1994): Orthogonal Series Expansions of Random Fields in Reliability Analysis, Journal of Engineering Mechanics, ASCE, 120(12), 2660-2678.

Zhu, W. Q. and Wu, W. Q. (1990): A Stochastic Finite Element Method for Real Eigenvalue Problems, in Stochastic Structural Dynamics 2, edited by Elishakoff, I. and Lin, Y. K., Springer Verlag, New York.

Ziha, K. (1995): Descriptive Sampling in Structural Safety, Structural Safety, 17, 33-41.

Please address your comments or questions on this paper to: International Center for Numerical Methods in Engineering Edificio C-1, Campus Norte UPC

Gran Capitán s/n

08034 Barcelona, Spain

Phone: 34-3-4016035; Fax: 34-3-4016517 